Disponível em www.scielo.br/paideia

\title{
A experiência da sexualidade em jovens adultos na França: entre errância e vida conjugal
}

\author{
Alain Giami \\ Institut National de la Santé et la Recherche Médicale, Paris, França
}

\begin{abstract}
Resumo: Este estudo se baseia em uma pesquisa qualitativa realizada com 24 estudantes franceses de 18 a 22 anos. No período de transição de suas vidas, rapazes e moças atravessam uma fase de errância, de experimentação afetiva e sexual, ao mesmo tempo em que aspiram a um ideal de vida conjugal. A errância sexual e afetiva constitui a prática e o sentido dados à sua experiência para uma importante parte das pessoas entrevistadas. A vida conjugal ou o estabelecimento de uma relação de casal monogâmica e estável constitui o ideal da maioria dos homens e mulheres entrevistados. A sexualidade é vivida, ao longo desse período de transição, como uma experiência de iniciação, às vezes difícil ou confusa e visa a construção de si e, mais a longo termo, do casal, mais que a uma multiplicação de experiências "recreativas".
\end{abstract}

Palavras-chave: Sexualidade. Amor. Relação sexual. Papéis sexuais.

\section{The experience of sexuality among French young adults: between wandering and married life}

\begin{abstract}
This qualitative study was carried out with 24 French students, ages between 18 and 22 years. During this transitional period of their lives, young adults experience a sexual and affective wandering phase, and at the same time, aspire to an ideal married life. Sexual and affective wandering refers to the experience and its meaning for the most part of those interviewed. A married life or establishment of a monogamous stable relationship is the ideal aspired by the majority of men and women interviewed. Sexuality is experienced, throughout this transitional period, as a sometimes difficult and confusing experience of initiation that aims the construction of the self, and in the long term, the construction of the couple, beyond multiple "recreational" experiences.
\end{abstract}

Keywords: Sexuality. Love. Sexual intercourse (human). Sex roles.

\section{La experiencia de la sexualidad en jóvenes adultos en Francia: entre errancia y la vida en pareja}

Resumen: Este estudio se basa en una investigación cualitativa realizada con 24 estudiantes franceses de 18 a 22 años. En este periodo de transición de sus vidas, los muchachos y las muchachas atraviesan una fase de errancia, de experimentación afectiva y sexual, al mismo tiempo aspirando a un ideal de vida en pareja. La errancia sexual y afectiva constituye la práctica y el sentido dado a su experiencia para una importante parte de las personas entrevistadas. La vida en pareja o, el establecimiento de una relación de pareja monogámica y estable, constituye el ideal de la mayoría de los hombres y de las mujeres entrevistadas. La sexualidad es vivida, a lo largo de este período de transición, como una experiencia de iniciación, a veces difícil o confusa e tiene por objeto la construcción de si y, más a largo plazo, de la pareja, más que una multiplicación de experiencias "recreativas".

Palabras clave: Sexualidad. Amor. Relación sexual. Roles sexuales. 


\section{Introdução}

Em uma revisão da literatura sobre as pesquisas feitas na França acerca da sexualidade e os comportamentos sexuais no contexto da aids, tínhamos colocado em evidência que um grande número de trabalhos quantitativos, utilizando questionários, tinham sido realizados na população geral e que um grande número de pesquisas qualitativas, utilizando entrevistas ou observações etnográficas, tinha sido realizado no seio de grupos populacionais considerados como mais expostos ao risco do HIV e dificilmente acessíveis por meio de pesquisas utilizando questionários. Pudemos, assim, notar um hiato entre as pesquisas feitas com a população geral (Analyse des Comportements Sexuels en France [ACSF] Análise dos Comportamentos Sexuais na França e Knowledge, Attitudes, Beliefs, Practices [KABP] Conhecimento, Atitudes, Crenças, Práticas, principalmente), que permanecem centradas na questão dos comportamentos sexuais (sobretudo os comportamentos de risco), no uso do preservativo, nas atitudes em relação às pessoas portadoras do vírus HIV e nas representações da doença aids, e as pesquisas qualitativas, que exploram em detalhes as significações sociais e psicológicas da sexualidade e das relações entre parceiros (Giami \& Schiltz, 1996).

A questão das mudanças na atividade sexual permanece centrada na análise da evolução da utilização do preservativo e sobre a redução do número de parceiros sexuais (Giami, 1998). Ao mesmo tempo, refletimos a respeito da enorme influência da representação epidemiológica da sexualidade nas pesquisas sobre os comportamentos sexuais (Giami, 1993), que têm como postulado implícito que a preservação da saúde constitui a principal preocupação dos indivíduos e a principal significação atribuída à atividade sexual. Em 1994, em um relatório realizado sob encomenda do Ministério da Saúde, a Rede Nacional de Saúde Pública se interrogava a respeito da aceleração da difusão da epidemia do HIV na população heterossexual (Brunet, Bourdillon, \& Costagliola, 1994). Do nosso ponto de vista, e tendo em conta que a maioria dessas novas infecções se produziam por meio da transmissão sexual, seria importante trazer respostas de peso para a questão das preocupações relativas à aids nas experiências e nas práticas sexuais desta população.

Pareceu-nos, assim, necessário desenvolver pesquisas que possibilitem a compreensão da significação da sexualidade no contexto da aids, no seio de uma amostra de população que não tenha sido constituída a partir de critérios relativos às características sexuais, mas a partir de critérios não sexuais, baseados na faixa etária e no fato de estar inserida em uma instituição educativa, uma universidade localizada nos subúrbios (zona norte) de Paris.

Além do mais, e na mesma época, vacinas contra o HIV começaram a ser testadas, sob os cuidados da Agência Nacional de Pesquisas sobre a aids, e surgiram questionamentos sobre o desenvolvimento de métodos que permitissem a constituição, o acompanhamento e a fidelização de redes de "voluntários sadios" que pudessem participar destes testes (Giami \& Lavigne, 1998). É nesta perspectiva que elaboramos um instrumento de pesquisa, contando com a colaboração de um serviço de Medicina Preventiva, que garantisse o recrutamento sistemático, a seleção e o acompanhamento da população pesquisada, viabilizando, dessa maneira, a repetição da coleta de dados após certo intervalo de tempo.

Fizemos uma tentativa de associar, em um mesmo instrumento, uma pesquisa principalmente qualitativa, baseada na coleta de dados aprofundados e múltiplos no contexto de um pequeno número de indivíduos, e um enquadramento da amostra pesquisada nas diferentes populações de referência nas quais ela se situa: população geral da França, população de estudantes universitários. Estudamos, entre outros temas, as motivações para participar da pesquisa, domínio pouco explorado, que permite aperfeiçoar a compreensão da participação em uma pesquisa sobre a sexualidade.

Este artigo não aborda a questão das modificações dos comportamentos sexuais com o impacto da aids, mas objetiva descrever e analisar a experiência 
da sexualidade, como ela é relatada por um grupo de jovens adultos, no sentido de identificar se e como a inquietação com a aids integra as preocupações em torno do estabelecimento e da consumação de relações sexuais, além do significado - ou não - do simbolismo da aids nesta experiência.

Constatamos que a questão da aids, notadamente a prevenção da infecção, não foi a principal preocupação evocada pelas pessoas que tinham sido longamente entrevistadas a respeito da sua experiência sexual, e que ela não serviu de fio condutor na elaboração dos relatos de experiência dessas pessoas. Usufruindo de um material de pesquisa bem detalhado sobre a experiência da sexualidade, analisamos certas dimensões: os relatos e biografias sexuais, as dificuldades e modalidades de iniciar a vida sexual e de estabelecer relações com o outro, os modos de autoproteção, os modos de comunicação sobre a sexualidade entre gerações e entre pares e as motivações em participar de uma pesquisa sobre a sexualidade. Outros temas foram também explorados na pesquisa inicial: a utilização conjugada de contraceptivos e de preservativos e sua evolução ao longo da relação, a influência dos pares e irmãos. Entretanto, tais temas não serão retomados no presente artigo.

\section{A construção da pesquisa}

\section{A influência do tema da aids nas pesquisas sobre sexualidade}

Desde o início da construção de estratégias de prevenção contra o HIV, as ciências sociais e psicológicas trouxeram contribuições importantes para as pesquisas a respeito da sexualidade e, mais particularmente, sobre a modificação dos comportamentos sexuais (Bajos, Bozon, Ferrand, Giami, \& Spira, 1998). Desde 1988, Gagnon notou que o desenvolvimento das pesquisas sobre a sexualidade, no contexto da aids, geraria trabalhos voltados ao conhecimento da sexualidade através do prisma da aids, mais do que o conhecimento dos problemas ligados à epidemia a partir de questões sobre a sexualidade (Gagnon, 1988). Esta reformulação das problemáticas de pesquisa em ciências sociais constituiu uma atualização das maneiras anteriores de tratar a sexualidade, em referência a um risco social ou a um risco de saúde, ou seja: gravidez de adolescentes, doenças sexualmente transmissíveis, disfunções sexuais (Ericksen \& Steffen, 1999; Gagnon, 2000; Giami, 1994; Michaels \& Giami, 1999). Nesse contexto, a atividade sexual foi reconceitualizada, principalmente sob o ângulo dos riscos existentes em relação às possibilidades de contaminação pelo HIV (Bajos, 1998).

Um lugar central foi assim atribuído ao tema da aids em uma representação epidemiológica da sexualidade, na qual os comportamentos sexuais são considerados como fatores de risco. Esta representação levou a pensar, em alguns casos, que o tema da aids e, em contraponto, aquele da preservação da saúde, constituía a principal significação atribuída à sexualidade. Esta maneira de pensar os problemas da sexualidade vem colocar em segundo plano ou mesmo ocultar as diferentes funções, práticas e simbólicas que preenchem a atividade sexual no plano social e cultural (Manderson, Bennett, \& Sheldrake, 1998), dando primazia a um discurso preventivo de Estado, enquanto matriz de significações culturais e subjetivas da sexualidade, em relação a outros sistemas simbólicos (Henriksson, 1995). Por exemplo, enunciados como "o amor constitui um obstáculo à utilização do preservativo" ou "amor: fator de risco", ilustram perfeitamente a hierarquização e a organização das significações associadas à sexualidade em torno do ponto central que constitui a utilização do preservativo e a preservação da saúde em relação a outras significações associadas à sexualidade, tal como o amor. Lembremos que para aproximadamente $80 \%$ dos homens e das mulheres interrogados na pesquisa ACSF, o amor permanece sendo a principal significação associada ao termo sexualidade (Spira, Bajos, \& Groupe Analyse des Comportements Sexuels en France [ACSF], 1993).

Além disso, os trabalhos baseados na problemática da aids permitiram um desenvolvimento sem precedentes das pesquisas sobre a sexualidade. A questão da aids permitiu, assim, desenvolver trabalhos 
sobre as relações sociais, sexuais e de poder reveladas com respeito à negociação do uso do preservativo (Holland, Ramanazoglu, Scott, Sharpe, \& Thompson, 1991), sobre as identidades sexuais e as diferentes formas de atividade sexual (Messiah \& MouretFourme, 1993) e contribuiu para dar maior visibilidade para a questão da homossexualidade masculina (Pollak \& Schiltz, 1991).

Um dos objetivos desta pesquisa foi desvincular a questão da experiência da sexualidade e da aids, no sentido de não mais examinar a sexualidade do ponto de vista da aids, mas, ao contrário, de incluir o questionamento sobre a sexualidade em outros conjuntos de significações e abordar a preocupação com a aids e a prevenção da infecção pelo vírus HIV em relação a um conjunto de significações sociais e psicológicas mais globais relacionadas à sexualidade. No plano metodológico, esta concepção foi concretizada pela decisão de não fazer perguntas sobre o tema da aids, por ocasião das entrevistas semi-estruturadas, de maneira a dar às pessoas interrogadas a possibilidade de se expressarem livremente sobre o tema. Por outro lado, o tema da aids foi objeto de questões detalhadas nos questionários, que foram utilizados em paralelo. Construímos, então, um instrumento de pesquisa no qual as pessoas recrutadas para as entrevistas foram informadas várias vezes, de maneira direta e indireta, de nosso interesse pelo tema da aids, sem que este fosse objeto específico de interrogação durante as entrevistas.

Sexualidade, atividade sexual e experiência da sexualidade

A não ser em contextos particulares (situação em laboratório, práticas sexuais em público, pornografia), a atividade sexual não pode ser observada diretamente. O que torna problemático e abusivo o uso do termo comportamento para designar o que é observado, ou seja, as declarações do autor (Giami, 1997). Os sociólogos americanos Gagnon e Simon elaboraram o conceito de conduta sexual (Gagnon \& Simon, 1973) para entender a complexidade da ação no campo da sexualidade, não excluindo a intencionalidade subentendida. Os mesmos autores elaboraram ulteriormente o conceito de script sexual para compreender como os enredos atuam na orientação e na realização das condutas sexuais (Gagnon, 2006).

Foucault estabeleceu que o termo sexualidade foi inventado no âmbito médico (Foucault, 1976). Esse termo, que apareceu na metade do século XIX, em francês, assim como em inglês, associa, em um mesmo conceito, a diferença de sexos, os fenômenos relativos à procriação e os comportamentos ligados à satisfação erótica, de acordo com o Dicionário Robert. O discurso médico estabeleceu a norma do instinto sexual submetido ao primado da genitalidade e da reprodução. As designações e intervenções médicas consistiram sobretudo na repressão ou na inibição de outras condutas sexuais, ou seja, as condutas sexuais que não visam a procriação, tais como a masturbação, a homossexualidade e as várias aberrações sexuais. A heterossexualidade como tipo de relações e de práticas entre pessoas de sexos diferentes sem intenção procriadora foi assim incluída no registro das aberrações sexuais. Somente a partir de 1930, sobretudo com os trabalhos de Kinsey (Kinsey, Pomeroy, \& Martin, 1948) que o conceito de heterossexualidade começou a designar a normalidade sexual, ou seja, a forma de comportamento sexual mais comum na população (Giami, 1999). O comportamento sexual foi definido como toda prática sexual visando a obtenção do orgasmo.

\section{As definições de atividade sexual}

Na pesquisa ACSF a noção de atividade sexual foi definida assim:

Uma atividade sexual designa toda atividade física ou mental ligada à excitação sexual de ao menos uma pessoa (carícias, masturbação, penetração, sites de trocas de mensagens sexuais, leitura de revistas eróticas...). Entre as atividades, distinguem-se as práticas sexuais, tipos de contatos corporais não necessariamente mútuos, ligados à excitação sexual, de ao menos uma pessoa 
(carícia do corpo, masturbação, penetração...). Uma relação sexual é uma atividade sexual que implica ao menos duas pessoas e que compreende no mínimo uma prática sexual. Uma relação sexual é uma relação que liga duas pessoas que têm relações sexuais juntas. Um parceiro sexual é uma pessoa com a qual se tem, ao menos uma vez, uma relação sexual (Bajos, Bozon, Giami, \& Ferrand, 1993, p. 33).

Essa definição de atividade sexual foi completada pelas noções de script e de significações:

Cada script se apresenta como uma série de atividades e de práticas sexuais, em um contexto dado, com um parceiro dado; trata-se de representações que os indivíduos têm das experiências sexuais que eles viveram ou desejaram viver, bem como daquelas que eles não viveram ou não desejaram viver. Práticas e atividades sexuais são organizadas em repertórios cujos elementos podem ser encenados em palcos distintos, segundo a natureza da relação sócio-sexual. Por significação, entende-se os valores e as funções atribuídas, conscientemente ou não, à atividade sexual. De acordo com as situações, pode-se considerar que a atividade sexual exprime um desejo de procriação, que ela contribui para reforçar uma relação nascente, ou que ela permite a satisfação de um desejo ou de uma pulsão... Para certos indivíduos, ela é a ocasião de confirmar sua maturidade sexual ou seu poder social. Significações variadas, às vezes contraditórias, podem coexistir no repertório de um mesmo indivíduo. Elas evoluem em função das diferentes experiências e da cultura nas quais se encontram (Bajos e cols., 1993, p. 34).

Essa definição é interessante porque estabelece uma abordagem multidimensional da atividade sexual, que leva em conta os aspectos comportamentais, a dinâmica das relações e a influência de certos aspectos sócio-mentais individuais e interindividuais. Entretanto, os aspectos qualitativos da atividade sexual e suas ancoragens ideológicas e fantasmáticas não foram sistematicamente levados em conta nessa tentativa de definição. As ciências sociais se interessaram particularmente pelas variações da atividade sexual segundo o ângulo das condutas (Kinsey e cols., 1948). Os historiadores e os antropólogos trataram das significações sociais e simbólicas dos atos sexuais. Alguns psicanalistas se interessaram em estudar as motivações e as significações subjetivas da sexualidade. Nesse contexto, Stoller propõe a distinção entre os aspectos que dizem respeito à identidade de gênero e aqueles que dizem respeito ao registro erótico.

Pode-se, de uma maneira geral, dividir os fenômenos comumente designados sob o termo vago de "sexualidade" em duas classes diferentes de conceitos: os estados que revelam o que se chama de "identidade de gênero" (masculino, feminino), e os que são "eróticos". O termo "erótico" é utilizado em um sentido ordinário e comum; ele diz respeito a uma qualidade que alguém reconhece consciente ou préconscientemente como agradável, sensual, e que, em um momento ou outro, será associado a uma excitação genital, redobrada de um desejo de satisfação intensa, cujo orgasmo é o melhor testemunho (Stoller, 1993).

A questão do "erótico" não pode ser reduzida somente às dimensões do prazer ou da sensação agradável. Stoller (1993) colocou em evidência a complexidade dos componentes que favorecem a excitação sexual e, principalmente, em certos casos, a presença de hostilidade ou do desejo de prejudicar. A perversão é, assim, definida como a "forma erótica do ódio".

Definir a sexualidade e suas diferentes significações: sociais, simbólicas, psicológicas; não seria limitar-se a uma redução da sexualidade aos atos sexuais. Por um lado, a qualificação de certos atos como sexuais é sujeita a variações sociais, históricas e situacionais (Sanders \& Reinisch, 1999). O caso Clinton-Lewinski colocou em evidência que se podia não considerar as práticas orais ou a exibição e as carícias dos seios como sendo atos sexuais. Além do 
mais, Devereux tinha relatado um caso no qual a presença simultânea de um homem e de uma mulher no espaço fechado de uma consulta psiquiátrica, ao abrigo de olhares, mostrou-se impossível devido à atribuição de uma significação sexual a esta situação, pelas pessoas que se encontravam nas proximidades (Devereux, 1980). Partimos, então, de uma definição aberta e ampla da experiência de sexualidade, não reduzida aos comportamentos sexuais, a fim de estudar como a sexualidade é representada e vivida pelas pessoas que entrevistamos.

\section{Um período específico da vida}

Se sabemos relativamente pouco sobre a vida afetiva e sexual da faixa etária dos 18-22 anos, vários trabalhos analisaram, em detalhes, os processos psicossociais que constituem a passagem da adolescência à idade adulta. A maioria desses trabalhos foram realizados ao longo dos anos 1980. Le Bras falava de uma - interminável adolescência e de intrigas familiares - o prolongamento da adolescência, marcado pela continuidade da moradia com os pais, o prolongamento da duração dos estudos, o aumento da idade da obtenção do primeiro emprego, do casamento e da procriação, testemunharam um prolongamento da dependência afetiva e social e a conservação das jovens gerações excluídas das decisões (Le Bras, 1983).

Béjin (1993) evoca paralelamente os anos indecisos da pós-adolescência, ao longo da qual a maior parte dos indivíduos passam, insensivelmente, da adolescência a uma aparente maturidade, atravessando uma idade mal definida que podemos denominar pósadolescência. Período consagrado às experiências, mas durante o qual evita-se tomar decisões importantes (Béjin, 1983). Os demógrafos analisaram o processo por meio das transformações da entrada na nupcialidade principalmente com o aparecimento da co-habitação juvenil. Mais tarde os autores evocaram a possibilidade de uma vida conjugal sem cohabitação, que marca a identificação de uma nova etapa no alongamento do desenvolvimento da entrada na idade adulta e de um retardamento na tomada de decisão (Leridon \& Villeneuve-Gokalp, 1994). Villeneuve-Gokalp descreve, a partir de uma pesquisa feita com jovens de 18 a 25 anos, as modalidades de acesso à idade adulta, ou seja, um processo de inserção profissional, familiar e social que começa com o fim da escolaridade e pode ser considerado como terminado com a obtenção de um emprego estável e o casamento (Villeneuve-Gokalp, 1982).

A autora analisa, entre outros temas, a significação da continuação da habitação entre gerações e as modalidades de partida da família. A metade dos jovens habita na casa dos pais porque eles encontram nesta co-habitação mais vantagens do que inconvenientes. Outra metade, ao contrário, prefere ter uma residência própria. Mas, tanto em um caso quanto no outro, a natureza do relacionamento entre pais e filhos, mesmo se não é desprezível, não foi um elemento determinante na decisão que foi tomada. Na maioria dos casos, a partida não foi motivada por "más relações" entre gerações (VilleneuveGokalp, 1982).

Nos estudos qualitativos, Giami, Berthier e Gosselin (1987) analisaram como os pós-adolescentes ou jovens que estão se tornando adultos ainda não fixados em uma relação amorosa estável, não engajados no processo da procriação, se encontram em um momento crucial de sua evolução pessoal e social. Neste período, obrigados a se afastarem da adolescência e se para esforçando para tal, eles tateiam o terreno para se tornarem adultos e encontrarem um lugar, uma identidade e ligações que reconheçam como próprias, com uma relativa autonomia. Sair da adolescência e tornar-se adulto é um processo evolutivo de experiências, tentativas e erros, e não uma modificação breve, socialmente marcada e reconhecida. Analisando esse período de transição em uma sociedade em evolução, os autores mencionados notam que é impossível compreender essa passagem sem levar em conta a experiência vivida por cada um, esta encruzilhada, este fosso onde se elabora e pode se ver em ação o trabalho primordial que constitui a criação continua de si (Giami e cols.,1987). 
Esses autores mostram que, em um certo período de extensão, de simultaneidade, de "vai-e-vem" das diversas etapas da passagem à idade adulta, esses jovens adultos aparecem, no seu conjunto, como um sistema em tensão entre o engajamento e o desligamento. Este estudo confirma que a pós-adolescência parece ser um tempo de pesquisa de si, do outro, de experiências múltiplas, tempo de crise para jovens adultos mantidos em uma dependência parental (alongamento da duração dos estudos, entrada na vida ativa retardada) em contradição com seus desejos de independência (Giami e cols., 1987).

Os relatos dos jovens adultos confirmam a idéia de que não se pode identificar uma ruptura nítida entre adolescência e estado adulto (Giami e cols., 1987). Os ritos de passagem que outrora balizavam a vida, dando os pontos de referência, tais como as primeiras experiências sexuais, o casamento em vestido de noiva branco, o fim dos estudos, o primeiro trabalho, o serviço militar, não constituem mais os pontos de passagem ritualizados em referência aos quais poder-se-ia tornar-se adulto. Entretanto, parece que "ter um filho" pode ser compreendido como um rito de passagem que conservaria toda a sua importância e sua significação. O filho representaria uma ancoragem identificável: "antes do filho", "depois do filho". Esta dinâmica é imaginada como uma página que se vira, um passar de um estado a outro que pode ser pensado como: ser pai ou mãe é tornar-se adulto.

Battagliola, Brown e Jaspard (1997), no estudo sobre os "itinerários de passagem à idade adulta", definem a juventude como uma fase de transição ao longo da qual se efetua uma dupla passagem: do fim da escolaridade à entrada no mercado de trabalho, da saída da casa dos pais à formação do casal e à constituição de uma família. Mesmo se persistentes, essas etapas não são ultrapassadas por todos os indivíduos; elas constituem, de todo modo, as balizas mais significativas na direção da autonomia e as prerrogativas ligadas ao status de adulto. Os autores mostram que os limiares de passagem evoluem: por um lado, eles se tornam menos nítidos e deixam de ser irreversíveis; por outro lado, eles são desmistificados.
Eles situam os jovens adultos em uma posição intermediária e descrevem a passagem da juventude à idade adulta em termos de "idas e voltas". Existe um adiamento no tempo do conjunto das etapas (prolongamento de um período de latência entre a saída do sistema escolar e a inserção no emprego, e entre a saída da casa dos pais e a formação de uma família) e uma imbricação dos calendários escolares, profissionais e privados:

As gerações estão em posição intermediária aos olhos das transformações globais dos modos de passagem à idade adulta; prolongamento da escolaridade, desenvolvimento do status intermediário entre a escola e o emprego e aumento do desemprego entre os jovens que procuram se inserir no mercado de trabalho; tendência a galgar mais tardiamente as etapas da vida privada e, sobretudo, aquela da constituição da família. (...) Os limiares de passagem claramente identificáveis e datados com precisão, tendem a serem substituídos pelas transições às fronteiras menos nítidas e desmistificadas. (...) Entre o fim da escolaridade e a obtenção de um emprego de mais de seis meses, tendem a se intercalar status mais incertos, como os estágios ou os empregos arrumados. A saída da casa dos pais se torna mais progressiva, o casamento direto se faz raro e é, na maior parte das vezes, precedido de formas mais informais de vida conjugal. Somente o nascimento de uma criança pode ser datado precisamente. Identificar os limiares significativos, datá-los e organizá-los em uma cronologia coerente torna-se então mais difícil que anteriormente, quando os limiares eram mais fortemente institucionalizados (Battagliola e cols., 1997, p. 87).

Bozon (1991), que estuda o novo lugar da sexualidade na composição do casal, aborda igualmente os processos de constituição da vida conjugal em 
termos de etapa, de fase, de passagem e de limiar. Este autor identifica um período de co-habitação parcial, que se traduz por uma latência mais longa entre as primeiras relações sexuais e a co-residência completa. De fato, as primeiras relações sexuais não levam imediatamente à co-habitação, mas introduzem mais a uma fase de co-habitação parcial, durante a qual cada parceiro conserva sua moradia, mesmo se passam uma boa parte do tempo juntos. As relações sexuais precoces introduzem uma forma intermediária de casal, que não co-habita, não funda uma vida comum (Bozon, 1991).

Levinson (1997) analisou as trajetórias sexuais dos jovens adultos com a ajuda de indicadores temporais recolhidos por intermédio de um calendário das relações sexuais com os diferentes parceiros. A autora descreve a dinâmica do estabelecimento de uma relação, desde os primeiros momentos do encontro, e coloca em evidência que o tipo de relação entrevisto orienta a seleção de um tipo, ou de outro, de parceiro, como se se tratasse de um programa. A escolha do parceiro pode ser efetuada em função do tipo de relação desejado, segundo se trate de uma relação breve ou duradoura. Levinson mostra, assim, que no contexto atual, a possibilidade de ter vários parceiros ao longo da vida é socialmente aceitável e freqüentemente desejável; esta pluralidade de encontros relativiza a importância simbólica da primeira relação sexual. Ela indica, enfim, que a organização temporal das primeiras relações sexuais é fundada sobre a distinção entre relação longa e relação breve, e também sobre a diferenciação dos sentimentos que estas recobrem. A relação amorosa é uma relação durável, a relação curta é aquela da sexualidade por excelência. Esta distinção é subjacente às trajetórias-tipo que caracterizam a passagem da primeira relação sexual à segunda (Levinson, 1997).

Battagliola e cols. (1997) mostram que nos meios populares e nas classes médias, as moças se comprometem mais raramente do que os rapazes na vida conjugal e familiar antes da obtenção do primeiro emprego. Isso corresponde, para esses autores, à tentativa de ter acesso a uma qualificação profissional e a um emprego por parte das moças, que ocorre paralelo a um questionamento mais global das relações entre os sexos no quadro familiar. (...) Nas gerações recentes, as jovens mulheres tentam levar adiante a rentabilização profissional de seu diploma e a vida conjugal e familiar. Socialmente autônomas, não esperam que seus cônjuges lhes assegurem o status social, nem prioritariamente, nem desde o início da vida em comum (Battagliola e cols., 1997, p. 99).

Nos diferentes trabalhos realizados ao longo das décadas de 1980 e 1990, a juventude é apreendida como um período intermediário, uma situação transitória, de passagem, de crise, uma sucessão de etapas, de status, que se caracterizam pelo vago e pela desmistificação das relações amorosas (simultaneidade, "vai-e-vem", imbricação e "ida-volta").

\section{Interpretar os dados}

Muitos anos se passaram entre o momento em que o projeto de pesquisa foi elaborado (primavera de 1995), aquele no qual as entrevistas foram realizadas (inverno de 1996 e primavera de 1997), e aquele em que a análise dos materiais recolhidos e a redação do relatório final foram feitas (em 2000). A evolução do nosso ponto de vista de pesquisa acompanhou o movimento cultural desses últimos anos, marcado pela diminuição da referência à aids nos debates sobre a sexualidade e pela aparição de novas problemáticas sociais da sexualidade.

Desde a primavera de 1998, os discursos públicos sobre a sexualidade conheceram mudanças importantes nos diferentes domínios. A entrada no mercado do Viagra levou a uma renovação das questões sobre a sexualidade. A atenção se voltou para os temas da performance sexual e da atividade sexual das pessoas idosas, temas que tinham sido deixados de lado nos trabalhos e nos discursos realizados no contexto cultural da aids. Além disso, enquanto a problemática 
da prevenção da aids visava o estabelecimento de controles restritivos sobre a atividade sexual caracterizada pela promiscuidade e pelos múltiplos parceiros, e se felicitava pela redução do número de parceiros, o Viagra (compreendido como fenômeno cultural e simbólico) ocasiona, desde então, discursos que deixam entrever o desenvolvimento e o aumento das freqüências da atividade sexual, em um contexto recreativo, podendo se associar à ingestão de substâncias lícitas e ilícitas. Nesse contexto, o restabelecimento de uma atividade sexual satisfatória e o tratamento das perturbações sexuais das pessoas atingidas pelos vírus HIV constituiu uma reviravolta radical na perspectiva do seu tratamento. A diminuição da morbidade e o recuo da mortalidade precoce parecem ter dado à vida sexual um lugar central na vida dessas pessoas (Lallemand, Salhy, Linard, Giami, \& Rozenbaum, 2002).

Assim, como recorda Dannecker (2000), as coisas mudaram desde o início da epidemia. A aids não é mais sistematicamente associada a uma representação da morte e ao medo desta, que constituíam um elemento importante nas motivações que levavam à adoção de comportamentos preventivos. $\mathrm{O}$ aparecimento das multiterapias e a diminuição da morbidade e da mortalidade que delas decorreram, transformaram profundamente as representações da aids e da prevenção, nos planos coletivo e subjetivo. Por um lado, o estudo dos desejos, das fantasias sexuais e da dinâmica das relações reencontra certa legitimidade para compreender as significações da atividade sexual e, por outro lado, os poderes públicos manifestam uma incerteza em relação à evolução - em baixa - dos comportamentos preventivos no contexto do aparecimento dos novos tratamentos.

As campanhas de prevenção desenvolvidas ao longo do verão de 1998 parecem ter sido sensíveis a um discurso que recoloca no primeiro plano a temática do erotismo, do prazer sexual e da performance com conotações humorísticas. Estamos bem longe de certas mensagens de prevenção elaboradas no início dos anos 1980, nos países anglo-saxões, que agitavam o espectro da morte a fim de comprometer os destinatários das mensagens de prevenção no abandono das práticas sexuais de risco.

Mais recentemente, outros temas ocuparam os debates sobre a sexualidade, principalmente as questões da pedofilia, da pornografia e dos impactos sobre os jovens que a elas se expõem precocemente, sobre as violências sexuais (estupros coletivos entre adolescentes e violências sexuais no seio do casal). Essa situação conduziu certos observadores a considerar que a sexualidade vem sendo, cada vez mais, percebida e construída socialmente sob o ângulo da violência. Além disso, as condutas sexuais minoritárias, tais como as trocas de casais, o sadomasoquismo consensual, ou o extremismo dos múltiplos parceiros descritos no livro A vida sexual de Catherine M., conquistaram as mídias e aumentaram a erotização da sociedade e da cultura.

Os debates públicos relativos à homossexualidade também deixaram o domínio da aids e abordaram a questão da união entre pessoas de mesmo sexo e adoção de crianças. O Pacs (contrato de união civil que pode ser feito entre parceiros homossexuais, amigos ou irmãos) foi definitivamente adotado pelo Parlamento francês em 1999. A questão da prevenção da aids entre homossexuais masculinos foi discutida por ocasião da difusão das teorias do bareback, ou seja, da não-utilização voluntária do preservativo, inclusive quando os indivíduos se sabem portadores do vírus HIV.

Como podemos ver a partir deste breve resumo, a aids não é mais o principal tema a partir do qual a sexualidade é discutida e interpretada no espaço público e nas pesquisas em ciências socais. Além disso, é surpreendente constatar que uma parte desses debates gira em torno de situações apresentadas como extremas ou minoritárias em relação ao número de pessoas que as vivem efetivamente. Esses debates se inscrevem em uma retórica que associa e opõe a valorização dessas situações extremas e a sua denúncia moral. As mídias contribuem assim para uma erotização permanente da vida em sociedade, procurando estímulos eróticos nas situações cotidianas de trabalho, de deslocamento, de lazer e de consumação. 


\section{Método}

\section{Participantes}

Participaram do estudo 24 jovens, de ambos os sexos (dezessete mulheres e sete homens), com idade entre 18 e 22 anos, estudantes de uma universidade da periferia parisiense.

\section{Procedimento}

Os principais avanços metodológicos desta pesquisa dizem respeito à complementaridade dos métodos utilizados. Utilizamos, conjuntamente, entrevistas semi-estruturadas e questionários com questões fechadas. Esta abordagem abriu aos pesquisadores a possibilidade de conduzir as entrevistas com maior liberdade, pois eles puderam estar voltados para a escuta da expressão das pessoas sobre os temas e os domínios de escolha delas, sem ter que se preocupar de re-enquadrar prematuramente a exploração na direção dos elementos identificados anteriormente nas hipóteses. Proposto no fim da entrevista, o questionário permitia a coleta de dados padronizados, principalmente comportamentais, de maneira a ter elementos para responder, sistematicamente, a algumas de nossas preocupações. As motivações que sustentam a aceitação da participação em uma pesquisa são pouco conhecidas. Na medida em que a maioria das pesquisas sobre a sexualidade são fundadas na seleção, mais ou menos sistemática, de pessoas que são voluntárias, ignoramos por quais razões essas pessoas aceitam a proposição dos pesquisadores. Inversamente, ignoramos as razões pelas quais as pessoas recusam-se a responder às proposições de pesquisa. Análises posteriores colocam em evidência que as motivações apresentam traços comuns com aquelas que sustentam a participação em pesquisas científicas sobre outros temas; ambas são organizadas em torno de uma dialética sutil entre a procura de um benefício pessoal, suscitado pelo fato de poder se exprimir, e um certo altruísmo, ligado ao sentimento de tornar-se útil para a coletividade. A situação de entrevista, que foi construída em nossa pesquisa, pode ter permitido a alguns participantes encontrar um espaço de expressão do tipo psicoterapêutico, reforçado pelo fato de que foram vários encontros.

$\mathrm{O}$ instrumento desta pesquisa foi elaborado associando uma equipe de pesquisadores com objetivos científicos próprios, e um serviço de saúde pública. Inscrevendo a seleção dos participantes em uma instituição de saúde, pudemos identificar as pessoas que aceitaram essa proposição e aquelas que a recusaram. Verificamos que a constituição de uma população de inquérito para uma pesquisa qualitativa pode ter uma dimensão sistemática que permite identificar com precisão as características da população estudada.

Enfim, nossa associação com o Centro de Medicina Preventiva permitiu a construção de um instrumento que assegure a seleção e o acompanhamento de voluntários que aceitem participar de uma pesquisa sem benefício direto. O método elaborado nesta ocasião poderia ser reproduzido por ocasião de outra pesquisa, necessitando da constituição de um recorte.

\section{Resultados e Discussão}

\section{A diversidade das experiências da sexualidade}

$\mathrm{O}$ que nos ensinam essas 24 entrevistas com jovens, entre 18 e 22 anos, estudantes de uma universidade da periferia parisiense? Em primeiro lugar, essas pessoas se situam num período da vida pouco estudado, aquele que se segue, para a maioria deles, ao que nós chamamos de entrada na sexualidade: três quartos deles já haviam tido relações sexuais. Além disso, este período precede o estabelecimento da vida conjugal: se uma parte deles já conheceu relações amorosas continuadas durante certo tempo, nenhum deles ainda viveu casado, ou seja, co-habitou com outra pessoa de maneira autônoma e prolongada.

Neste período da vida, nós sabemos, graças aos dados da pesquisa ACSF, que, de maneira global, os estilos de vida sexual dos jovens franceses desta faixa etária são muito diversificados: uma parte deles não teve nenhuma experiência de relações sexuais, outros só tiveram um único parceiro, e outros ainda 
tiveram dois ou mais parceiros. Nota-se também grandes diferenças entre homens e mulheres (entre 2024 anos, $43 \%$ dos rapazes declaram ter tido mais de seis parceiras, contra somente $12 \%$ das moças; por outro lado, $43 \%$ das moças declaram não ter tido nenhum parceiro ou somente um, contra $23 \%$ dos rapazes dessa mesma faixa etária).

As entrevistas biográficas e os questionários aplicados refletem também a diversidade de práticas e de relações, mas permitem, entre outras coisas, decifrar as significações que os indivíduos dão às suas experiências e os contextos biográficos nos quais elas se inscrevem.

Assim, observamos configurações de experiências sexuais muito diferentes. O que fez com que alguns tenham permanecido virgens. Pode ter sido uma escolha pessoal ou ideológica, ou o resultado das circunstâncias que fazem que esses jovens reconhecidamente manifestem uma incapacidade de manter relações sexuais. Aqueles que tiveram alguns parceiros (entre dois e quatro) dizem ter tido relações que foram mais efêmeras e que tiveram lugar devido a disposições psicológicas do momento, ou em circunstâncias que favoreceram este tipo de encontro. Enfim, no grupo, mais restrito, dos rapazes e das moças que tiveram mais de dez parceiros sexuais, a multiplicação dos parceiros pode ter figuras bem diferentes: pode tratar-se de relações efêmeras, entretidas nos momentos de errância e descompromisso, na ausência de uma relação amorosa, ou em períodos particulares, que se seguiram à ruptura de uma relação amorosa, ou ainda, uma maneira de gerar "amizades coloridas", de querer descobrir a sexualidade, ou de ter emoções fortes.

Além disso, enquanto algumas pessoas tiveram relações com uma duração prolongada (um ano ou mais), em um contexto de monogamia, encontramos outras pessoas que tiveram um grande número de parceiros (uma dezena) no espaço de alguns meses, antes de se abster de toda relação, ou de se comprometerem numa relação monogâmica duradoura. Ainda mais, ao longo do período que separa as duas séries de entrevistas, não foi raro verificar que relações tenham sido rompidas ou que as pessoas tenham pensado em romper uma relação existente.

A maioria dos entrevistados continuava a morar com os pais, no domicílio familiar; a entrada na faculdade não constituiu ruptura com o grupo de amigos do colégio e da adolescência. Nenhuma das pessoas que entrevistamos tinha filhos; duas mulheres declararam terem feito uma interrupção voluntária da gravidez.

Os métodos de prevenção do HIV se inscrevem na dinâmica da evolução da relação como uma passagem obrigatória no começo desta, antes de uma estabilização da relação, indo da prática do teste de rastreamento ao abandono da utilização do preservativo, que marca um contrato de confiança e de fidelidade. O preservativo pode constituir, em certos casos, um elemento de discórdia entre os parceiros: quando as moças declaram que os rapazes são reticentes em utilizá-lo, enquanto elas o fazem voluntariamente. Entretanto, esta forma de racionalização da sexualidade não é repartida de maneira homogênea entre todas as pessoas estudadas e observamos que os conflitos em matéria de utilização do preservativo revelam, freqüentemente, um conflito ou uma insatisfação com a relação considerada no seu conjunto.

\section{As diferenças segundo o gênero}

As mulheres representam dois terços das pessoas que aceitaram ser incluídas na pesquisa. Esta proporção aparece bem representativa da estrutura da população discente da universidade na qual a pesquisa teve lugar, assim como a estrutura da população que utiliza o Serviço de Medicina Preventiva. Não observamos uma super-representação das mulheres entre os voluntários que participaram das entrevistas. No entanto, as mulheres e os homens diferem no plano da experiência sexual. Uma maior proporção de rapazes nunca teve relações sexuais e amorosas. Entre os que se declararam virgens, os rapazes constituíam a maioria nessa situação, seja devido às circunstâncias ou devido aos seus problemas psicológicos, enquanto que as moças informaram tratar-se 
de uma opção, baseada nos ideais amorosos ou nas crenças religiosas. A virgindade é então abordada mais serenamente pelas moças do que pelos rapazes e é vivida como uma escolha positiva na espera do grande amor ou de um parceiro sério e estável.

Algumas moças evocaram um episódio de abuso sexual ao longo da infância ou em ocasião recente (3/17). Somente um rapaz se apresentou como homossexual, reivindicando a sua identidade gay e retraçando o percurso do reconhecimento e da construção de sua orientação sexual. Ele relatou longamente um episódio de violência homofóbica que sofreu quando adolescente, que o traumatizou severamente e cujos efeitos ainda se faziam sentir. Duas mulheres evocaram relações homossexuais passageiras, sem se apresentarem nem se reivindicarem como homossexuais e sem que os episódios tenham tido consequiências notórias sobre a evolução das mesmas.

De maneira mais geral, pudemos observar uma certa diferença entre os homens e as mulheres. Com exceção de uma minoria entre as mulheres que declarou ter permanecido virgem, as entrevistadas tiveram uma experiência sexual quantitativamente maior do que os homens. Elas tiveram mais freqüentemente a experiência de uma ou mais relações amorosas significativas que terminou, na maioria dos casos, com uma ruptura. Algumas delas também tiveram a experiência de um maior número de parceiros (uma dezena) do que os rapazes. Inversamente, uma maior proporção de rapazes ainda era virgem e nenhum rapaz heterossexual declarou ter tido um tão grande número de parceiras.

A maior diferença entre os homens e as mulheres reside na diferença de atitude entre eles em relação à natureza das relações neste período da vida. Os rapazes e as moças exprimiram um ideal amoroso baseado na constituição de um casal monógamo, comprometido em uma vida comum e com um projeto de ter filhos. Porém, enquanto os primeiros consideram que suas relações devem desde já se inscrever nesta perspectiva, as segundas consideram, por sua vez, que o momento ainda não chegou. Elas desejam ter uma relação amorosa que não constitua obstáculo à sua independência, nem à vontade de desenvolverem experiências de diferentes naturezas (intelectuais, sociais e sexuais). As moças que conheceram uma ruptura, da qual tiveram a iniciativa, declararam terse encontrado em uma situação sufocante, rotineira, que ameaçava o desenvolvimento de sua independência delas. Esta situação apareceu com muita força naquelas provindas da imigração ou de departamentos de além-mar, que rejeitam maciçamente o modelo de submissão da mulher às exigências dos homens e das famílias. Os rapazes reafirmaram as virtudes do modelo do casal moderno, baseado na igualdade e na satisfação sexual e afetiva, e compromissado na construção de uma família; mas as moças pensam que é preciso aproveitar dessa fase da vida marcada pela realização de experiências.

Apesar desta diversidade de tipos de relações sexuais e amorosas, pudemos observar a importância e o impacto dos ideais amorosos tradicionais que associam o amor, a atividade sexual, a vida em casal e o projeto familiar. Esse modelo permanece igualmente ainda muito impregnado nas moças e nos rapazes. Esses ideais amorosos tiveram impactos diferentes nos dois sexos. Para algumas moças, o ideal pode ter como função justificar a preservação da virgindade ou da abstinência temporária na espera do "príncipe encantado", enquanto que, para outras, trata-se de um projeto para o futuro, ao sair de um período no qual elas tiveram vontade de viver de maneira independente investindo nos estudos e no estabelecimento de relações sociais. Diante de tal projeto, uma relação fechada demais, imposta pelo rapaz, parece inapropriada ou prematura. Inversamente, várias das moças que entrevistamos se queixam da falta de sinceridade e da mentira dos rapazes que mantêm relações paralelas sem dizer a elas. Os rapazes que ainda são virgens aparecem mais neuróticos ou inibidos nas suas capacidades de ter uma relação amorosa com uma moça e se fecham em um universo fantasmático ou no vazio de uma posição depressiva. Não encontramos "paqueradores" inveterados, que procuram acumular as relações umas depois das outras. No entanto, alguns rapazes pareceram desestabilizados pelo desejo de independência das suas parceiras. 
Enfim, as mulheres pareceram muito mais implicadas na gestão de suas relações em função de exigências relativamente identificadas e exprimidas. Por sua vez, os homens pareceram muito mais emaranhados nos seus conflitos internos, enquanto alguns estão ainda muito aquém na capacidade de estabelecer uma relação, tanto sexual como amorosa.

\section{Considerações finais}

Tradicionalmente, as pesquisas norte-americanas sobre a sexualidade foram construídas em torno da noção de sexualidade conjugal (marital intercourse), considerada por Alfred Kinsey como a principal forma de atividade sexual para homens e mulheres, e aquela que traria a maioria dos orgasmos ao longo da existência. A sexualidade conjugal representava, para Alfred Kinsey, entre outros autores, a norma em relação a qual as outras formas de relações sócio-sexuais eram definidas e avaliadas como relações pré-conjugais ou extra-conjugais. Esta construção científica da sexualidade reflete as normas sociais da sociedade norte-americana, na qual o casamento continua a constituir a principal forma de organização social legítima da sexualidade, a instituição privilegiada na qual a atividade sexual se desenvolve principalmente para a maioria da população adulta (Gagnon, Giami, Michaels, \& Colomby, 2001). O emprego do conceito de sexualidade pré-conjugal implica, implicitamente, que o conjunto da atividade sexual permanece orientado em torno da finalidade do casamento, que o casamento constitui a principal ocasião na qual se desenvolve a atividade sexual, e que o casamento consiste na principal fonte de significação atribuída à atividade sexual. Será que ainda faz sentido hoje em dia, na França, considerar os tipos de atividade sexual (heterossexual) que se desenvolvem fora do casamento como atividades sexuais pré-conjugais?

A errância e a vida conjugal são dois termos que se impuseram a nós no final desta pesquisa para designar a experiência da sexualidade dos estudantes nos tempos da aids. A referência e a predominância da noção de vida conjugal para ponderar a experiência sexual dos jovens estudantes podem surpreender no contexto atual, que coloca ênfase sobretudo na diversidade de experiências sexuais, compreendendo notadamente a multiplicação dos parceiros, as trocas de parceiros, o desenvolvimento do interesse pelo fetichismo e pelo sadomasoquismo, os abusos e as violências sexuais. Todavia, os dois termos, errância e vida conjugal, não devem ser compreendidos no mesmo nível de experiência. Se a errância sexual e afetiva, que diz respeito à noção de monogamia em série, constitui a prática e o sentido dado à experiência de uma parte importante das pessoas que interrogamos, a vida conjugal não se situa, ainda, no mesmo nível da prática efetiva. A vida conjugal ou, mais precisamente, o estabelecimento de uma relação monógama e estável, lugar de uma relação amorosa consolidada, constitui o ideal e a aspiração da maioria dos homens e mulheres que entrevistamos. A vida conjugal estaria se impondo como norma ideal, na medida em que essas pessoas pensam e analisam a atual experiência que vivenciam, ainda aquém de uma prática efetiva da vida conjugal almejada.

Essa pesquisa traz uma resposta mista a esta questão: a vida sexual dos jovens adultos não é redutível à vida conjugal. Entretanto, para a população dos jovens estudantes, que tivemos a oportunidade de interrogar longamente nesse trabalho, a vida de casal, a co-habitação, o casamento e a constituição de uma família representam os horizontes intransponíveis da vida sexual, o objetivo a alcançar no fim do desenvolvimento e da ascensão à maturidade. Trata-se de certa forma de um ideal a atingir. Esse ideal tanto pode facilitar a experiência atual da vida sexual e afetiva das pessoas, colocando-a em perspectiva, quanto pode constituir uma barreira que a desvalorize. Em outras palavras, a experiência sexual dos jovens interrogados, que nós pudemos estabelecer como sendo representativa de sua faixa etária e de seu grupo social, oscila entre a prática da errância, qualificada de monogamia em série, e a vida conjugal idealizada.

Por fim, a utilização conjunta de dois métodos fundados sobre princípios diferentes, entrevistas biográ- 
ficas e questionários, permitiu, entre outras coisas, identificar incoerências e contradições em certas declarações que diziam respeito a temas precisos, tais como a experiência de uma interrupção voluntária de gravidez (aborto feito legalmente na França), o número de parceiros declarados, ou o fato de ter experimentado (ou não) relações sexuais. Esta abordagem permitiu, assim, melhor compreender as vantagens e os limites de cada um dos métodos utilizados na presente pesquisa.

\section{Referências}

Bajos, N. (1998). Les risques de la sexualité. In N. Bajos, M. Bozon, A. Ferrand, A. Giami \& A. Spira (Eds.), La sexualité aux temps du Sida (pp. 35-61). Paris: PUF.

Bajos, N., Bozon, M., Ferrand, A., Giami, A., \& Spira, A. (Eds.). (1998). La sexualité aux temps du sida. Paris: PUF.

Bajos, N., Bozon, M., Giami, A., \& Ferrand, A. (1993). Orientation de la démarche de recherche. In A. Spira, N. Bajos, \& Groupe-Analyse des Comportements Sexuels en France (Eds.), Les comportements sexuels en France (pp. 29-44). Paris: La Documentation Française.

Battagliola, F., Brown, E., \& Jaspard, M. (1997). Itinéraires de passage à l'âge adulte: Différence de sexe, différence de classe. Sociétés Contemporaines, 25, 85-103.

Béjin, A. (1983). De l'adolescence à la postadolescence: Les années indécises. Le Débat, 25, 126-132.

Bozon, M. (1991). La nouvelle place de la sexualité dans la constitution du couple. Sciences Sociales et Santé, 9(4), 69-88.

Brunet, J. B., Bourdillon, F., \& Costagliola, D. (1994). Evolution de l'épidémie à VIH en France dans la population hétérosexuelle (Rapport au Ministre délégué à la Santé). Saint-Maurice: Réseau National de Santé Publique.
Dannecker, M. (2000). Contre le déni du désir sexuel. Infothek, 1, 4-10.

Devereux, G. (1980). De l'angoisse à la methode dans les sciences du comportement. Paris: Flammarion.

Ericksen, J., \& Steffen, S. (Eds.). (1999). Kiss and tell: Surveying sex in the twentieth century. Cambridge: Harvard University Press.

Foucault, M. (1976). Histoire de la sexualité. Tome 1: La volonté de savoir. Paris: Gallimard.

Gagnon, J. (1988). Sex research and sexual conduct in the era of Aids. Journal of AIDS, 1, 593-601.

Gagnon, J. (2000). Theorizing risky sex. In J. Bancroft (Ed.), The role of theory in sex research (pp. 149-176). Bloomington: Indiana University Press.

Gagnon, J. (2006). Uma interpretação do desejo: Ensaios sobre o estudo da sexualidade. Rio de Janeiro: Garamond.

Gagnon, J., Giami, A., Michaels, S., \& Colomby, P. (2001). A comparative study of the couple in the social organization of sexuality in France and the United States. Journal of Sex Research, 38(2), 24-34.

Gagnon, J., \& Simon, W. (1973). Sexual conduct. Chicago: Aldine.

Giami, A. (1993). Le questionnaire ACSF: L'influence d'une représentation épidémiologique de la sexualité. Population, 48, 1229-1256.

Giami, A. (1994). De Kinsey à AIDS: A evolução da construção do comportamento sexual em pesquisas quantitativas. In M. A. Loyola (Ed.), Aids e sexualidade: O ponto de vista das ciências humanas (pp. 209-240). Rio de Janeiro: Relume.

Giami, A. (1997). Description et observation. In R. Mendès-Leite \& P. O. de Busscher (Eds.), Microgéographie sexographique de deux backrooms parisiennes (pp. 5-11). Lille: Gay Kitch.

Giami, A. (1998). Les impacts du sida sur la sexualité. Panoramiques, 34, 162-170. 
Giami, A. (1999). Cent ans d'hétérosexualité. Actes de la Recherche en Sciences Sociales, 128, 38-45.

Giami, A., Berthier, F., \& Gosselin, F. (1987). Emprise et dégagement de la famille d'origine: Post adolescents ou jeunes adultes? Bulletin de Psychologie, 382(18), 851-856.

Giami, A., \& Lavigne, C. (1998). Recusa de engajamento nas testagens de vacinas contra o HIV. Horizontes Antropológicos, 9, 203-235.

Giami, A., \& Schiltz, M. A. (1996). Representations of sexuality and relations between partners: Sex research in France in the era of AIDS. Annual Review of Sex Research, 7, 125-157.

Henriksson, B. (1995). Risk factor love: Homosexuality, sexual interaction and HIV prevention. Goteborg: Goteborgs Universitets Skriftserien.

Holland, J., Ramanazoglu, C., Scott, S., Sharpe, S., \& Thompson, R. (1991). Between embarrassment and trust: Young women and the diversity of condom use. In P. Aggleton, P. Davies \& G. Hart (Eds.), AIDS: Responses, interventions and care (pp. 127-148). London: Farmer Press.

Kinsey, A., Pomeroy, W., \& Martin, C. (1948). Sexual behavior in the human male. Philadelphia: Saunders.

Lallemand, F., Salhy, Y., Linard, F., Giami, A., \& Rozenbaum, W. (2002). Sexual dysfunction in 156 ambulatory hiv-infected men receiving highly active antiretroviral therapy combinations with and without protease inhibitors. Journal of Acquired Immune Deficiency Syndromes, 30, 187-190.

Le Bras, H. (1983). L'interminable adolescence ou les ruses de la famille. Le Débat, 25, 116-125.

Leridon, H., \& Villeneuve-Gokalp, C. (1994). Constance et inconstances de la famille. Biographies familiales des couples et des enfants. Paris: INED.
Levinson, S. (1997). L'organisation temporelle des premières relations sexuelles. In $\mathrm{H}$. Lagrange \& B. Lhomond (Eds.), L'entrée dans la sexualité: Le comportement des jeunes dans le contexte du sida (pp. 227-254). Paris: La Découverte.

Manderson, L., Bennett, L., \& Sheldrake, M. (1998). Sex, social institutions and social structure: Anthropological contributions to the study of sexuality. Annual Review of Sex Research,10, 184-209.

Messiah,A., \& Mouret-Fourme, E. (1993). Homosexualité, bisexualité: Éléments de socio-biographie sexuelle. Population, 48, 1353-1379.

Michaels, S., \& Giami, A. (1999). Sexual acts and sexual relationships: Asking about sex in surveys. Public Opinion Quarterly, 63, 385-404.

Pollak, M., \& Schiltz, M. A. (1991). Six années d'enquêtes sur les homos et bisexuels masculins face au Sida: Questions de méthode. Bulletin de Méthodologie Sociologique, 31, 32-48.

Sanders, S., \& Reinisch, J. M. (1999). Would you say you "had sex" if...? Journal of the American Academy of Medicine, 281, 275-277.

Spira, A., Bajos, N., \& Groupe-Analyse des Comportements Sexuels en France (Eds.). (1993). Les comportements sexuels en France. Paris: La Documentation Française.

Stoller, R. (1993). Dynamiques des troubles érotiques. InA. Fine,A.LeGuen \&A. Oppenheimer(Eds.), Les troubles de la sexualité (pp. 119-137). Paris: PUF.

Villeneuve-Gokalp, C. (1982). Quand vient l'âge des choix. Enquête auprès des jeunes de 18 à 25 ans: Emploi, résidence, mariage. Paris: INED.

Artigo recebido em 21/12/2007.

Aceito para publicação em 15/08/2008. 
$\mathrm{O}$ autor agradece à Profa. Dra. Laura Câmara Lima, do Departamento de Psicologia do Instituto de Educação da Universidade Federal do Mato GrossoUFMT, que gentilmente traduziu o manuscrito original para a língua portuguesa.

Endereço para correspondência:

Alain Giami. Institut National de la Santé et la Recherche Médicale-Inserm, U 822, 82 Rue du General - Leclerc - Le Kremlin Bicetre, f-94276, France. E-mail: alain.giami@inserm.fr

Alain Giami é diretor de pesquisa do Institut National de la Santé et la Recherche Médicale-Inserm, Paris, França. 